\title{
Beware! Preimplantation genetic diagnosis may solve some old problems but it also raises new ones
}

Heather Draper and Ruth Chadwick University of Birmingham and University of Central Lancashire, respectively

\begin{abstract}
Preimplantation genetic diagnosis (PIGD) goes some way to meeting the clinical, psychological and ethical problems of antenatal testing. We should guard, however, against the assumption that PIGD is the answer to all our problems. It also presents some new problems and leaves some old problems untouched. This paper will provide an overview of how PIGD meets some of the old problems but will concentrate on two new challenges for ethics (and, indeed, law). First we look at whether we should always suppose that it is wrong for a clinician to implant a genetically abnormal zygote. The second concern is particularly important in the UK. The Human Fertilisation and Embryology Act (1990) gives clinicians a statutory obligation to consider the interests of the future children they help to create using in vitro fertilisation (IVF) techniques. Does this mean that because PIGD is based on IVF techniques the balance of power for determining the best interests of the future child shifts from the mother to the clinician?

(Fournal of Medical Ethics 1999;25:114-120)
\end{abstract}

Keywords: preimplantation genetic diagnosis; reproductive control; new genetics; best interests of future children

\section{Preimplantation genetic testing}

Preimplantation genetic diagnosis (PIGD) is the result of combining our increasing knowledge about the human genome with techniques employed in assisted conception. It is currently employed when a couple have had one affected child and/or one or more termination of pregnancy (TOP) following conventional antenatal testing. Superovulation, egg collection and in vitro fertilisation (IVF) are followed by the genetic testing of each of the resulting embryos. Non-affected embryos are then implanted using the same protocols covering IVF for infertility. Preimplantation genetic diagnosis enables couples to found their family with greater confidence that they will neither give birth to an(other) affected child nor subject themselves to a series of terminations of pregnancy.
Advantages of preimplantation diagnosis The most obvious advantage of PIGD is that enables couples to have an unaffected child withi out also having to have a series of terminations of pregnancy. These terminations can be particularl\$ stressful for a woman (and her partner) becaus $\underline{\overrightarrow{\mathrm{e}}}$ each aborted fetus is potentially a wanted childs Moreover, the knowledge that each pregnancy is. conditional upon a clear test result also constraing the usual joy with which news of a new pregnancf is greeted by those "trying for a baby". The potential of PIGD to reduce the physical and psyo chological wear and tear on the woman and hem partner is one advantage. Another is that the faile ure to implant an embryo is viewed by many a 9 morally preferable to the killing of a more full developed fetus. This view is attractive to thos who believe that the embryo gradually acquires greater moral status as it develops both physically. and towards viability - hence the various cut-of points in its development which have been used to demark appropriate behaviour (the primitive streak for embryo research or the increased abilit/, to exist independently which seems to mark tho cut-off point for termination of pregnancy etc) Preimplantation genetic diagnosis is also attrac? tive to those who wish to draw a distinction between actively destroying life (termination of pregnancy) and a failure to save life (the decisios not to implant an embryo). Indeed, we speak of "allowing embryos to perish" rather than "embry killing".

There remains, however, a sizeable contingen for whom PIGD does not resolve any ethica problems because for them, morally significant human life begins at conception. Obviously thos holding this view may be as opposed to PIGD a they are to IVF, unless they are prepared to endorse "embryo euthanasia". According to thiQ view, the human embryo has a moral status akin t\& that of the fetus, infant or fully developed humarf This position need not be incompatible with the view that what makes life worth living is its qualits 
Thus, it could both be held that the embryo has moral significance and that it is in the best interests of the embryo that it is not implanted, provided that its life is not worth living. Such a view might also justify termination of a pregnancy (feticide) or non-voluntary euthanasia (of both small infants and incompetent adults).

Another perceived advantage of preimplantation diagnosis is that it gives greater choice to couples because it gives them the scope to make a decision about which of the embryos to implant, whereas TOP simply presents the choice of whether or not to terminate a pregnancy. This choice is, as we will show, somewhat of a mixed blessing. On the positive side it enables couples to maximise the advantages for their future child but within the limits of what nature provides (ie the number of embryos they have to choose between). So, whilst not actually manipulating the genes of their offspring, they are able to choose not to implant, for instance, not just those embryos which will be directly affected by some genetic disorder, but also any embryo which carries recessive genes for some disorder. Thus, parents are able to protect their future children not just from the direct burdens of genetic disorder, but also the worries which they have themselves experienced to ensure that their own children will not suffer. In time couples may even be able to select according to other genetic traits just as they can now select the sex of their future progeny.

Of course, even as these perceived advantages are listed, old problems begin to emerge. It is one thing to accept, as some people do, that no injustice is done to the embryo if it is not implanted. It is quite another to endorse the policies and justifications which motivate the decision not to implant. For instance, what counts as a life not worth living? Is sex selection permissible? What makes a particular genetic formation a disorder rather than a difference? Is it permissible to maximise advantage as well as to minimise disadvantage? Should we be eradicating difference or intolerance to difference? These larger questions cut across the debate even if we are prepared to accept that no one of moral significance is affected by our decision not to implant any one of the embryos in question. We do not intend to dwell on these old problems, but intend instead to explore some of the new problems which PIGD has introduced, concerning whether it is always wrong to implant an affected embryo; and the extent to which PIGD involves a transfer of power away from women. There is also a third problem, concerning the greater potential for eugenic implications in PIGD because of the possibility that embryos might be selected on the basis of carrier status for recessive conditions, but this will not be discussed here for reasons of space.

\section{First new problem: is it always wrong to implant an affected embryo?}

It would be easy to assume that the purpose of PIGD is to ensure that only unaffected children are born, and that since the rationale for desiring this end is to avoid the life of suffering which affected children are perceived to have, in the absence of available and effective treatment for the condition in question, it must be wrong to deliberately or knowingly implant an affected embryo. It is one thing, it could be argued, for couples to refuse to undertake PIGD, but quite another for them to request that an affected embryo be implanted. The assumption that it is wrong knowingly to implant an affected embryo seems to be a shift away from the rhetoric of choice which dominates when the context is counselling concerning termination of pregnancy. Yet if it is so obviously wrong to implant an affected embryo, why is it not equally obviously wrong to continue to term under similar circumstances? One answer is that embryos have less moral worth than fetuses. Another is that termination is wrapped up with the autonomy of women whereas the ex-utero embryo is the responsibility of the clinician. We will return to this point later. The assumption that it is obviously wrong to implant affected embryos also ignores at least two other issues in the wider debate about reproductive technologies. The first is the extent to which parents can expect - where possible - to be genetically related to their offspring. The second is the extent to which we are prepared to entertain debate about what makes a life worth living, what constitutes a disadvantaged life, and under what circumstances, if any, an individual could be said to be harmed by being brought into existence.

Let's put this into the context of some examples.

1. Simon and Claire are both in their mid-40s. They have been referred for PIGD because ten years ago they had a child with Fragile $\mathrm{X}$ who died six months ago. Since the birth of this child, Claire has had two TOPs following positive antenatal tests for Fragile X. Following the death of their first child, they are more than ever determined to extend their family, but acknowledge that time is running out for them. Claire is superovulated but even so only five gametes are collected. Only two of these become fertilised when mixed with Simon's sperm. Both embryos are affected by Fragile X. Simon and Claire decide that they are 
getting too old to wait any longer for a child and ask the clinician to implant the embryos. As an alternative, he offers them a place on his IVF waiting list, arguing that they should try IVF with donor gametes. They refuse because they want a child which is genetically related to both of them. $\mathrm{He}$ offers further PIGD, they refuse again, concerned that next time they may not even manage to produce a single embryo and that there is no guarantee that even if they do, it will be unaffected by Fragile X. They prefer instead to take the chance that this second child - if a pregnancy is established - will be less badly affected than was their first.

2. Judith and Paul are carriers for cystic fibrosis. They have both had experience of living with sufferers and want to avoid having an affected child. Following PIGD they are informed that they have six viable embryos, but one is affected with Down's syndrome. They ask for four of the embryos to be frozen for later use and for two of them to be implanted. They are not in the least concerned about Down's syndrome, saying that they believe that it is possible to have Down's and still have a good quality of life. They want the affected embryo to be implanted/frozen without discrimination and at random.

3. Philip and Linda are both deaf. Linda is infertile and the couple have been accepted for IVF. Once on the programme they were offered PIGD by a well-meaning clinician who assumed that they would not want any of their children to be deaf. $\mathrm{He}$ is shocked when they steadfastly insist that out of their nine embryos the one with congenital deafness be implanted first - along with any one of the other unaffected embryos. The remaining embryos should be frozen for later use. They justify their decision by arguing that their quality of life is better than that of the hearing. As far as they are concerned, giving preference to the affected embryo is giving preference to the one which will have the best quality of life. They are very concerned that any hearing child they have will be an "outsider" - part neither of the deaf nor of the hearing community at least for the first five or so years of his/her life.

CASE NUMBER 1: SIMON AND CLAIRE

This case challenges us to determine whether it is permissible for a couple to put the desire for a child which is genetically related to them above the interests of the child, once born; and also, whether it is acceptable to offset the risk that they will not manage to have another successful attempt against the risk that the child may have a very disadvantaged life. To address these issues, we have to look at reproductive freedoms antp parental responsibility.

There has been systematic and unresolved discussion over what makes an individual a paren $\overrightarrow{\overrightarrow{\vec{s}}}$ even more debate about what makes a woman mother. This discussion has been provoked b⿳亠े what is perceived as the division of motherhoo into, for instance, the social, the bearer and the genetic. Although most people agree that it is now a necessary criterion of parenting that one has a genetic relationship with a child, it is usually cons sidered a sufficient qualification. The strength of this assumption has been revealed in a variety of contexts: the "father" distressed because a woma is going to abort "his" child; the reluctance of some to donate genetic material or frozeno embryos; mothers who only reluctantly handed over children for adoption; men who discover that unbeknown to them, they have a child in the worla whom they have never met. Likewise, as many of those experiencing the discomfort and expense of infertility treatment attest, the desire to have genetically related child is an enormously strons one. From this perspective, it is not difficult to have sympathy with what Simon and Claire arg proposing to do.

Their claim does, however, highlight the weat ness of considering the conceptual issue of parenting in isolation from the responsibilitie which flow from parenting. Simon and Claire ar $\vec{E}$ asserting a right to be parents of a particular kin - genetic parents. Whether such a right exists an if so what its content might be is contested. ${ }^{2}$ Yet if such a right exists, it stands to protect the goods which flow from parenting. ${ }^{3}$ These goods are arguably of two kinds - the fundamental and the incidental. Incidental goods include goods which one obtains as a known side effect of having chiß dren; for instance, securing council housing, proo ducing a football team, or having company and security in one's old age. Fundamental goods, o⿱ the other hand, are the moral goods of parentingo the goods which parenting represent and whick? without parenting, might never be achieved These goods include the care and nurture of $\mathbb{E}$ child, the sense of affection and community found in loving families and the moral good of being responsible for the wellbeing of another. It is these kinds of goods which the concept of a right to parent seems to protect.

The question which Simon and Claire's cas raises is whether being genetically related to the child is an incidental or fundamental good of parenting. Or, put another way, does the right found a family include the right to be geneticallg related to one's child? On balance, the answer this question is no. Being genetically related 
one's child seems more appropriately located as an incidental good of parenting because it lacks sufficient weight to count as a fundamental good. This way of looking at the dilemma faced by Simon and Claire yields a quite different result from that which concentrates solely on future persons. In conclusion then, it would seem that Simon and Claire cannot insist upon having either of the embryos implanted on the grounds that they have a right to a child genetically related to them.

CASES 2 AND 3 JUDITH AND PAUL, PHILIP AND LINDA In some respects both of these cases raise the same issue - that there is no definitive view either about what makes a life worth living, or about what constitutes quality of life. These are not new issues. The new dimension in PIGD is the possibility of actively choosing to have an affected child; in Judith and Paul's case because they do not see Down's as a condition incompatible with quality of life; and in Philip and Linda's case, because they think that being deaf is positively lifeenhancing.

Of course, making an assessment of an individual's quality of life is a moral decision because other morally important decisions will be based upon the answer reached. In this respect, one has to look at the context in which the decision is being made to gain a full appreciation of the morality of the decision itself. So, for instance, if a quality-of-life decision is being used to allocate scarce resources, we want to locate this decision in the context of debate about justice. The context for our two couples is that they are claiming the parental authority to make decisions about the welfare of their children. The context in which their decision has to be discussed is that of whether they are making a responsible or irresponsible parental judgment. The moral basis for respecting the judgment of parents is the presumption that parents have the best interests of their children at heart, that they of all people can be trusted to do what is best for their children. This is the basis upon which parental judgments command moral authority. Sometimes parents do not seem to exercise good judgment when it comes to protecting their children's best interests. When this happens, we may consider them to be bad or even unfit parents, or sometimes no kind of parent at all! These kinds of judgments reinforce the view expressed above that it is almost impossible to look at what being a parent means without also considering parental responsibility. In this sense, not only might it be argued that the term parent is actually a moral term (as opposed to a term related to bearing, genetics or social roles), but also that it is perhaps inappropriate to separate our understanding of good parents from our understanding of what it means to be a parent. ${ }^{3}$ Whilst attractive, this leaves us in danger of denying that parents can make mistakes without losing, as it were, the right to parent. We have, therefore, to accept that parents can make misguided judgments as well as bad judgments. Also, because there is an acceptably wide understanding of what constitutes a child's best interests, different parents may arrive at different decisions for their children without being either misguided or irresponsible in their judgment.

Now we need to apply these observations to the decisions made by Judith and Paul, Linda and Philip. We will then be in a better position to determine whether it is wrong for them to want to have affected embryos implanted.

\section{JUDITH AND PAUL}

To assess the strength of Judith and Paul's claim, we may actually need to know more about their views about the status of the embryo. If they are making an embryo euthanasia decision (ie attempting to make a decision about the future quality of life for what they consider to be an existing child) and if they believe that Down's is compatible with a quality of life worth having, then we will have to accept that they are making a responsible parental judgment - whether or not it is the one which we would be prepared to make for our own child.

But what if they are making a more political statement - perhaps one about the wrongness of a policy of testing for Down's? This is a much more difficult issue to resolve because the couple are much more vulnerable to the criticism of harming the future child, particularly if they believe that the embryo itself has no moral status. Judith and Paul cast as proponents of embryo euthanasia are balancing the harm of ceasing to exist against the harm of existing with Down's. Judith and Paul cast as a couple who believe that the embryo does not have moral worth (because it does not yet have a life at all) seem rather to be choosing to create a person with Down's. We need to be aware that there are different points coming together here. First there is the issue unique to PIGD - that of the active choice to implant a particular embryo. Second is the old dilemma of the extent to which parents can allow their own political views to affect the decisions they take about reproduction, rather than being motivated by considerations of the interests of their future children.

It might be argued that since Down's syndrome is not deemed to be incompatible with a life worth living, Judith and Paul do not wrong a child by 
bringing it into existence with Down's. But however much value is attached to the lives of those who have Down's, it nevertheless remains the case that is it not good to have the disabilities which those who have Down's have to suffer. It is one thing to say that those who have Down's are valuable and quite another to say that the choice between choosing to implant an affected or an unaffected embryo has no moral significance. Whether a condition is so severe as to make life not worth living is one question. Whether it is permissible to implant an embryo with a condition that will result in disability, but a disability that is not so severe that it makes life not worth living, is another. If the answer is not clear then there is a case for leaving it to parental choice. There remains an issue, however, about the sorts of considerations that are relevant to that choice.

What if, however, they argue that for them the moral significance in having the affected embryo implanted lies precisely in making a political statement about the value of those with Down's, a symbol of their belief that a life with Down's is nevertheless a valuable life? We cannot do justice to the wider issue here, so we will simply describe it rather than discussing it at length. In its broadest sense this question asks us to decide which takes precedence, our obligations as citizens or our obligations as parents.

The extent to which we can impose the effects of our political beliefs on our children is raised in many different contexts. The conscientious objector in an oppressive regime knows that her objections place not just herself but her children at risk of physical harm and death. Those who believe in public education for children have to decide whether or not to send their children to private schools when their children have special needs or happen to live in the catchment areas of substandard state schools. We might be happy to conclude that making these decisions is one of those areas where, once again, the boundary for responsible parental decision making is quite a wide one. Nevertheless, we also conclude that once parents cite their moral authority as parents as the reason to allow them to make such decisions for their children, the interests of the children do have to figure to a significant degree in the calculations, whatever the final decision which is reached.

\section{LINDA AND PHILIP}

Linda and Philip also want to implant an affected embryo, but in their case what they believe themselves to be doing is maximising the advantages for their future child. This decision is a difficult one to challenge. By offering a choice between possible future persons, PIGD provides not only the opportunity to avoid avoidable harms, but als모 the possibility of maximising advantage or ent. hancing quality of life.

Why are Linda and Philip able to argue tha deafness is life-enhancing? One answer is that the are themselves deaf and are therefore in a good position to judge, whereas we who can hear are not. Equally, however, it could be argued tha Linda and Philip because of their deafness are nog in a position to appreciate what they are missing. In one sense this argument is intractable; it is impossible to claim that one form of life is bettert than another unless one has experienced both and even then one's preference could be said to bs subjective. One could, of course, refuse to givie their claim any credibility at all by arguing that it is harming a child to engineer that she is borm without the capacity to enjoy all of her senses of do all that it is possible for humans to do. ${ }^{4}$ This surely the kind of judgment to which we appeat when we observe that whatever value attaches to the life of the person with Down's, nevertheles having Down's is a disadvantage. But Linda an Philip's claim is more difficult to dismiss than this? Few if any of us claim that the pressure of intelle tual capacity is so great that we wish we'd bee born without it. We might claim that the pressures of responsibilities we have as a result are so greä that we'd like to give them up in favour of a more simple life, but in considering the possibilities fof this more simple life, irreversible brain damage rarely, if ever, features. Many of us have, howeve found noise to be obtrusive. Too much uninvited noise is itself a recognised medical condition (tir nitus) but too much intellectual capacity is nof Some of us regularly resort to ear-plugs in order ti sleep or work in environments we cannot contro\$. Thus whilst we do not literally deafen ourselves, we certainly are prepared to trade hearing for peace and quiet.

The argument, however, may be less in terms the quality of sound-related experience or its lac but as indicated above, in terms of a sense ơ belonging to a community, a language and a cuf ture. It is this that marks out deafness from othe conditions. Linda and Philip are not simply male ing a political claim that people like them should not be discriminated against through programmese to screen out deaf future persons, although there are arguments for the view that screening fof deafness harms the deaf community. They ar motivated by the genuine belief that they are ace ing in their child's best interests. Perhaps the bes that can be argued against them is that they shoul allow their child to decide for herself whether she thinks that their quality of life is better than her This choice is removed from her if she is bo 
irreversibly deaf. But even this solution does not address the point which they make about being an outsider.

This case highlights one of the disadvantages of giving parental decision making moral authority, namely that it can act as a trump card in those areas where there is no right answer, but where the decision which parents want to make, to choose a state in which a child is born with a hearing system which does not work, is one that most rational bystanders would not take. On the other hand, as has been suggested above, in cases where it is not the case that the child would be so disadvantaged that its life would not be worth living, it may be argued that parental choice is the best option, particularly where motivated by the child's best interests. It is precisely this that may be undermined by PIGD, however, and this is where we turn to our second problem.

\section{Second new problem: does PIGD shift reproductive power from women to physicians?}

To date, quality-of-life decisions have largely rested with women because it was impossible to make decisions over the life or death of fetuses without effecting these decisions on women's bodies. Once pregnant, a woman is free to decide whether or not to seek antenatal screening, and irrespective of this decision she is free (within legal boundaries) to determine whether or not the child is a wanted one, irrespective of any advice given to the contrary by her clinician. ${ }^{5}$ Although women cannot be compelled to participate in PIGD, once they have parted with their gametes and once the resulting embryos are tested, it is possible for them to lose control over what happens next. Clinicians participating in IVF have a clear statutory obligation (and some would argue that this reflects an absolute moral obligation) to consider the interests of the future child. Just as the clinician cannot compel a woman to give up her gametes, or have a TOP, or be implanted, she cannot compel him to implant embryos against his wishes. Does this mean that in all the cases we discussed above, we were wrong to assume that the decisions were the parents to make at all? The clinician, it seems, has the final say in whether or not to implant. ${ }^{6}$

Or does he? There are several points to be made here. The first concerns the extent to which the clinician needs to rely solely on his own judgment. He can of course take account of the arguments of the parents - or indeed, his own ethics committee. However, the net effect of this could be to split hairs, since although he takes account of the par- ents' views he still has the final power to decide whether or not to be bound by their decision. Also, the 1990 Human Fertilisation and Embryology Act was formulated on an assumption that the clinician would arrive at this judgment before deciding whether or not to treat. When disagreements arise in PIGD, treatment (if this is the correct term) is already well underway. Any dispute concerns whether or not to implant existing embryos. In deciding not to implant on the basis of disagreement about the interests of the future child, the clinician not only retains his considerable power over reproductive freedom, he also gains power over what could be described as the property of the couple - the embryo - which is the product of their own gametes, which arguably are their property.

But, is it fair to assume that if gametes are property embryos are also property? If we consider that the embryo has an independent moral status, the claim about ownership diminishes because we readily accept that humans cannot be owned in any sense. If, however, we are working on the assumption that the embryo has no independent moral status it does seem reasonable to suppose that it can be owned and therefore belongs to the couple jointly (let's leave aside totally the issue of what to do if they disagree among themselves). This puts the clinician in an impossible position. He cannot implant because he does not think that it is in the interests of the child to do so, equally he cannot simply freeze the embryo since the purpose of this would be to afford the couple the chance of successfully finding a clinician who will agree to implant and this may result in a child whose interests he believes are best served by not coming into existence. Both freezing and implanting are using his skills to bring about a child. Of course, there is a precedent for suggesting that he should freeze and refer, namely the practice of clinicians who have a conscientious objection to abortion but who are expected to offer to refer patients to someone who will perform an abortion for them. The moral inconsistency of this position is obvious and needs no further explanation.

It seems to us highly probable that this tension is likely to cause problems in the future. The couple will, not unreasonably, assume that the decision in the case of PIGD will be theirs to make - because in antenatal screening it is. Likewise, the clinician cannot be blamed for assuming that he has the final word since in infertility treatment he does. Moreover, it seems likely that any "contract" which the couple make with their clinician as part of their consent prior to PIGD will be impossible to enforce - particularly in a case like that of 
Simon and Claire, where the embryos in question became endowed with the additional status of being the ONLY chance for them to have a genetically related child. It remains to be seen, then, whether PIGD should be marketed as affording greater autonomy and reproductive freedom to couples when, as things stand, they are effectively putting the decision in the hands of the treating clinician.

\section{Acknowledgement}

Both authors would like to acknowledge the support of the Directorate General XII of the Commission of the European Communities under its Biomedicine and Health Research Programme (Biomed II). The authors gratefully acknowledge the stimulus and support provided by the commission.

Heather Draper, $B A, M A, P h D$, is Lecturer in Biomedical Ethics at the Centre for Biomedical Ethics, University of Birmingham. Ruth Chadwick, BPhil,
$M A$, DPhil, LLB, FRSA, is Head of the Centre fdr Professional Ethics, and Professor of Moral Philo $\bar{\hbar}$. sophy, University of Central Lancashire.

\section{References and notes}

1 For instance in the amendment to the Abortion Act 1967 found in the Human Fertilisation and Embryology Act 1990.

2 See for example, Chadwick RF, ed. Ethics, reproduction and genetic control [2nd ed]. London: Routledge, 1992.

3 For the complete development of this argument see Draper $\dot{H}$ Assisted conception techniques, parent selection and the inte $\vec{E}$ ests of children to adequate parents. Bioetica 1997;5:391-9. O

4 For a discussion of this issue see Chadwick R, Levitt MA. The end of deafness? Deaf people, deaf genes and deaf ethics. De Worlds 1997;13:2-9.

5 Granted, conditions such as extent of knowledge, subtle coecr cion, tests made available and other circumstances may erodo

6 Steinberg DL. Bodies in glass: genetics, eugenics, embryo ethic $\overrightarrow{\vec{H}}$ Manchester: Manchester University Press, 1997. As Deborat Lynn Steinberg has argued, while preimplantation diagnost may be debated in the gender-neutral language of genetic risks. it "obscures social inequalities between practitioners and female patients and between patients and their male partnere while implicitly reinforcing and relying on these pow imbalances".

\section{News and notes}

\section{Models of Teaching Biomedical Ethics: Can There be a Consensus?}

A workshop on this topic is to be held at Imperial College School of Medicine, London, on 20th April 1999, from 9 am to $5 \mathrm{pm}$.

The workshop is the final event in a three-year research project on European biomedical ethics education, funded by the European Commission and coordinated by Michael Parker and Donna Dickenson at Imperial College School of Medicine.

Samples of the workbooks will be available at the workshop. Speakers will include: Ann Sommerville (BMA), Tony Hope (ETHOX), Gwen Adshead (Broadmoor Hospital) and Ruud ter Meulen (Institute for Bioethics, Maastricht).

There is no charge for the workshop but places are limited. Lunch will be provided.

For more information please contact: Michael Parker on 01715943368 or by e-mail: m.j.parker $(a$ ic.ac.uk. 